\title{
Pathophysiologic and Therapeutic Perspectives Based on Thrombus Histology in Stroke
}

\author{
Ji Hoe Heo, ${ }^{\mathrm{a}, \mathrm{b}}$ Hyo Suk Nam, ${ }^{\mathrm{a}, \mathrm{b}}$ Young Dae Kim, ${ }^{\mathrm{a}, \mathrm{b}}$ Jin Kyo Choi, ${ }^{\mathrm{a}}$ Byung Moon Kim, ${ }^{\mathrm{b}, \mathrm{c}}$ Dong Joon Kim, ${ }^{\mathrm{c}}$ \\ Il Kwon ${ }^{\mathrm{b}}$ \\ ${ }^{a}$ Department of Neurology, Yonsei University College of Medicine, Seoul, Korea \\ 'Integrative Research Center for Cerebrovascular and Cardiovascular Diseases, Yonsei University College of Medicine, Seoul, Korea \\ 'Department of Radiology, Yonsei University College of Medicine, Seoul, Korea
}

\begin{abstract}
Recent advances in endovascular thrombectomy have enabled the histopathologic analysis of fresh thrombi in patients with acute stroke. Histologic analysis has shown that the thrombus composition is very heterogeneous between patients. However, the distribution pattern of each thrombus component often differs between patients with cardiac thrombi and those with arterial thrombi, and the efficacy of endovascular thrombectomy is different according to the thrombus composition. Furthermore, the thrombus age is related to the efficacy of reperfusion therapy. Recent studies have shown that neutrophils and neutrophil extracellular traps contribute to thrombus formation and resistance to reperfusion therapy. Histologic features of thrombi in patients with stroke may provide some clues to stroke etiology, which is helpful for determining the strategy of stroke prevention. Research on thrombus may also be helpful for improving reperfusion therapy, including the development of new thrombolytic agents.
\end{abstract}

Keywords Intracranial thrombus; Histology; Stroke; Thrombectomy
Correspondence: Ji Hoe Heo Department of Neurology, Yonsei University College of Medicine, 50-1 Yonsei-ro, Seodaemun-gu, Seoul 03722, Korea

Tel: +82-2-2228-1605

Fax: +82-2-393-0705

E-mail:jhheo@yuhs.ac

Received: December 6, 2019 Revised: January 22, 2020

Accepted: January 23, 2020

\section{Introduction}

Ischemic stroke is caused by cerebral artery occlusion. Thrombus is the primary cause of arterial occlusion and the main target of acute and preventive treatment in stroke. Thrombus is the end-product of thrombosis caused by diverse etiologies. In this sense, knowledge on thrombus may provide some insights into the mechanism of thrombosis and further ideas on the treatment of stroke.

Before mechanical endovascular era, the examination of thrombus was only possible postmortem and in very few patients. As such, knowledge on the characteristics of thrombus in stroke has been based on a conceptual idea of thrombus formation in different stroke etiologies. Traditional teaching on thrombus involved a simple categorization based on the domi- nant composition: red, white, and mixed; platelet-rich, fibrinrich, and erythrocyte-rich. Preventive treatment was also based on a simplistic and conceptual idea of thrombus formation that a thrombus of the arterial origin is platelet-rich and that of the cardiac origin, such as atrial fibrillation, is erythrocyte/ fibrin-rich. As a result, antiplatelet agents have been used for stroke prevention in those with suspected arterial etiology and anticoagulants in those with suspected cardiac etiology. However, the antemortem analysis of fresh thrombi is now possible in acute stroke patients.

The successful introduction of endovascular thrombectomy has improved the clinical outcomes of stroke patients. ${ }^{1}$ Moreover, it has markedly changed the care system and treatment strategy for acute stroke; these improvements include the extension of the therapeutic time window, use of advanced imaging for pa- 
tient selection, development of new thrombectomy techniques, prehospital diagnosis and triage of patients, and launching of the concept of a thrombectomy-capable stroke center. ${ }^{2-5}$

Recently, fresh thrombi have become obtainable during endovascular thrombectomy, and this availability has increased bench side research on thrombi. Earlier studies have focused on thrombus composition according to different stroke etiologies, as well as the association between imaging findings and thrombus histology. More recent studies have investigated treatment-related issues based on thrombus histology. The imaging of thrombus and correlation of imaging with the histopathology of thrombus in stroke have been extensively reviewed previously. ${ }^{6,7}$ Additionally, a consensus statement paper was also published on the analysis of thrombi in acute stroke. ${ }^{8}$

We herein review available literature on thrombus in stroke, including the thrombus composition and various stroke etiologies; leukocytes and neutrophil extracellular traps (NETs), which have recently emerged as a key player in thrombus formation; thrombus histology and the efficacy of reperfusion therapy; and pathophysiologic and therapeutic perspectives based on thrombus research.

\section{Thrombus composition and stroke etiology}

The characteristics of thrombus may somehow represent the pathophysiologic mechanism of thrombus formation. Several studies have attempted to determine stroke etiology based on histologic examinations of thrombi obtained during endovascular thrombectomy.

\section{Determined etiology}

Traditional teaching states that a thrombus of the cardiac origin is erythrocyte/fibrin-dominant due to a slow flow in the cardiac chamber, whereas that of the arterial origin is platelet-dominant due to a high flow at the stenotic arterial segments. Earlier studies have examined thrombi using hematoxylin and eosin (H\&E) staining. They showed that thrombi retrieved in stroke patients are heterogeneous and diverse, and failed to identify any difference in the histological features between thrombi of the cardiac origin and those of the arterial origin. ${ }^{9,10}$ Subsequent studies used histochemical and/or immunohistochemical staining to better identify each thrombus component. Most studies have focused on relative amounts of each thrombus component according to the stroke etiology. In a small case series, there were controversies in the dominant composition of thrombi between the cardiac and arterial thrombi. ${ }^{11-13}$ However, more recent studies with larger samples showed that erythrocyte domi- nancy was seen in the arterial or noncardiac thrombi and fibrin/ platelet dominancy in the cardiac thrombi (Table 1). ${ }^{14-16}$

Histologic findings of fresh thrombi obtained during mechanical thrombectomy suggest that the thrombus composition in large vessel occlusion in stroke is somewhat different from traditional teaching; that is, thrombi of both arterial and cardiac origins show a mixed red-white pattern, but erythrocyte dominancy is more frequent in arterial thrombi than in cardiac thrombi (Table 1). ${ }^{9-14,16-19}$

Leukocytes are often present in thrombus. leukocytes identified by H\&E staining are more dominant in cardiac thrombi. ${ }^{13,14,17,19}$ However, in studies that assessed T-cells and monocytes based on immunohistochemistry, the majority of T-cells and monocytes were detected in a random distribution in erythrocyte-rich areas and red clots. ${ }^{20}$ The number of T-cells was significantly higher in thrombi from the atherothrombotic group than in those due to other causes or cardioembolism groups. ${ }^{21}$ Leukocyte dominancy may partly depend on the thrombus age, in that older thrombi have more neutrophils than fresh thrombi. ${ }^{22}$ Thrombi with a high leukocyte fraction were related to more organized thrombi of the cardioembolic origin. ${ }^{17}$ In addition, leukocyte infiltration into the thrombus shifted from neutrophils to monocytes/macrophages in a venous thrombosis model in mice. ${ }^{23}$

\section{Cryptogenic and other etiologies}

A few studies have evaluated the thrombus composition in patients with cryptogenic etiology. There were no significant differences in the proportion of thrombus components between patients with an undetermined etiology and those with a cardioembolism or large artery atherosclerosis. ${ }^{17}$ However, other studies showed that similar histologic features between cryptogenic and cardioembolic stroke patients. ${ }^{13,14,19}$ Uncovered cardiac sources have been suggested as the main etiology of cryptogenic stroke. ${ }^{13}$ Although further studies are necessary, histologic findings of thrombi support the current understanding of the cryptogenic stroke etiology.

Some patients with active cancer develop stroke..$^{24} \mathrm{~A}$ recent study assessed thrombus composition using immunohistochemistry in patients with active cancer who underwent endovascular thrombectomy. ${ }^{25}$ Thrombus composition was compared between patients with active cancer, those with inactive cancer, and those without cancer. Patients with active cancer showed a higher platelet fraction and a lower erythrocyte fraction than those with inactive cancer or those without cancer. Patients with vegetation in the cardiac valve (nonbacterial thrombotic endocarditis [NBTE]) had very high platelet and low erythrocyte fractions. ${ }^{25}$ Similar findings have been shown in 
Table 1. Thrombus composition and etiology of stroke

\begin{tabular}{|c|c|c|c|c|c|c|c|}
\hline Study & $\begin{array}{l}\text { Patient } \\
\text { no. }\end{array}$ & Device & Staining method & $\begin{array}{c}\text { Analysis } \\
\text { (quantitation) }\end{array}$ & RBC-dominancy & $\begin{array}{l}\text { Fibrin/fibrin-platelet- } \\
\text { dominancy }\end{array}$ & Leukocytes \\
\hline $\begin{array}{l}\text { Marder et al. } \\
(2006)^{9}\end{array}$ & 25 & Merci & $\mathrm{H} \& \mathrm{E}$ & $\begin{array}{l}\text { Feature detection } \\
\text { analysis }\end{array}$ & $\begin{array}{l}\text { No differences } \\
\text { between etiologies }\end{array}$ & $\begin{array}{l}\text { No differences } \\
\text { between etiologies }\end{array}$ & \\
\hline $\begin{array}{l}\text { Liebeskind et al. } \\
(2011)^{10}\end{array}$ & 50 & Merci & $\mathrm{H} \& \mathrm{E}$ & Semi-automated & $\begin{array}{l}\text { No differences } \\
\text { between etiologies }\end{array}$ & $\begin{array}{l}\text { No differences } \\
\text { between etiologies }\end{array}$ & \\
\hline Sato et al. $(2012)^{18}$ & 17 & Autopsy & $\begin{array}{l}\text { IHC (fibit for fibrin, plate- } \\
\text { let glycoprotein Ilbllla } \\
\text { for platelets, glyco- } \\
\text { phorin A for RBC }\end{array}$ & Semi-automated & Cardiac & $\begin{array}{l}\text { No differences } \\
\text { between etiologies }\end{array}$ & \\
\hline $\begin{array}{l}\text { Niesten et al. } \\
(2014)^{11}\end{array}$ & 22 & $\begin{array}{l}\text { Merci, Trevo, } \\
\text { solitaire }\end{array}$ & $\begin{array}{l}\text { H\&E, Mallory's phospho- } \\
\text { tungstic acid-hematox- } \\
\text { ylin (fibrin) } \\
\text { IHC (glycophorin A for } \\
\text { RBC, CD31 for platelets) }\end{array}$ & Consensus & Arterial dissection & $\begin{array}{l}\text { No differences } \\
\text { between etiologies }\end{array}$ & \\
\hline Kim et al. (2015) & 37 & $\begin{array}{l}\text { Solitaire, } \\
\text { aspiration }\end{array}$ & $\begin{array}{l}\text { H\&E } \\
\text { IHC (CD61 for platelets) }\end{array}$ & Semi-automated & Cardiac & $\begin{array}{l}\text { Arterial (fibrin) } \\
\text { No difference (platelet) }\end{array}$ & No difference \\
\hline Ahn et al. $(2016)^{13}$ & 32 & Aspiration & $\begin{array}{l}\mathrm{H} \& \mathrm{E}, \mathrm{MSB}, \mathrm{IHC} \text { (CD42b } \\
\text { for platelets) }\end{array}$ & Semi-automated & Arterial & $\begin{array}{l}\text { Cardiac (fibrin) } \\
\text { Cryptogenic }\end{array}$ & Cardiac \\
\hline $\begin{array}{l}\text { Boeckh-Behrens et } \\
\text { al. }(2016)^{14}\end{array}$ & 137 & Not specified & H\&E, Elastica van Gieson & Semi-automated & Noncardiac & $\begin{array}{l}\text { Cardiac (fibrin-platelet) } \\
\text { Cryptogenic }\end{array}$ & Cardiac \\
\hline $\begin{array}{l}\text { Boeckh-Behrens et } \\
\text { al. }(2016)^{17}\end{array}$ & 34 & $\begin{array}{l}\text { Solitaire, } \\
\text { Trevo, } \\
\text { Penumbra } \\
\text { Pulse }\end{array}$ & H\&E, Elastica van Gieson & Semi-automated & ND & ND & Cardiac \\
\hline $\begin{array}{l}\text { Sporns et al. } \\
(2017)^{19}\end{array}$ & 187 & $\begin{array}{l}\text { pRESet stent } \\
\text { retriever }\end{array}$ & $\begin{array}{l}\text { H\&E, Elastica van Gieson, } \\
\text { Prussian blue } \\
\text { IHC (CD3, CD20, CD68) }\end{array}$ & Semi-automated & Noncardiac & $\begin{array}{l}\text { Cardiac (fibrin) } \\
\text { Cryptogenic }\end{array}$ & Cardiac \\
\hline $\begin{array}{l}\text { Maekawa et al. } \\
(2018)^{16}\end{array}$ & 79 & $\begin{array}{l}\text { Solitaire, } \\
\text { Trevo, Revive, } \\
\text { Penumbra }\end{array}$ & $\mathrm{HE}$ & Semi-automated & $\begin{array}{l}\text { Arterial } \\
\text { Cryptogenic }\end{array}$ & Cardiac (fibrin) & No difference \\
\hline
\end{tabular}

RBC, red blood cell; H\&E, hematoxylin and eosin; IHC, immunohistochemistry; MSB, Martius scarlet blue; ND, no description.

postmortem pathologic studies of vegetation in NBTE, which comprises a platelet mass with interwoven fibrin. ${ }^{26,27}$

The findings of high platelet and low erythrocyte fractions were also shown in patients with cryptogenic stroke etiology among those with active cancer. ${ }^{25}$ Stroke etiology is cryptogenic in approximately half of stroke patients with active cancer. ${ }^{28}$ In a large autopsy study of patients with stroke and cancer, NBTE was the most common etiology, comprising $51.3 \% .^{29}$ Altogether, these findings indicate that thrombus in cancer-associated NBTE is platelet-rich.

Information on thrombus histology in stroke patients with rare causes remains insufficient. In one study, three patients with arterial dissection showed mixed but erythrocyte-dominant thrombi. ${ }^{11}$ Further studies with larger sample sizes and diverse etiologies are necessary to better understand thrombus histology in stroke with different causes.

\section{Leukocytes and neutrophil extracellular traps}

Traditional teaching on thrombus formation has focused on platelets, erythrocytes, and fibrins. However, leukocytes are important players in thrombosis. Recent studies have demonstrated the role of neutrophils and NETs in thrombus formation. ${ }^{30}$ NETs are a web-like structure of deoxyribonucleic acid (DNA) fibers comprising histones and granules that are released by activated neutrophils (Figure 1). The primary role of NETs is to ensnare and kill pathogens. Recently, NETs have been shown to play an important role in arterial and venous thrombosis. ${ }^{31,32}$ Together with the fibrin meshwork, NETs form a scaffold of thrombus. NETs are also actively involved in thrombosis by their interaction with platelets, erythrocytes, and platelet adhesion molecules such as fibrinogen, von Willebrand factor, and fibronectin. ${ }^{32}$

Neutrophils and NETs are found in thrombi retrieved during mechanical thrombectomy, and they are frequently colocalized (Figure 2). On immunohistochemistry, NETs show different features among thrombi of stroke patients. They are seen as being confined within cells, in either filopodia-like or web-like structures (Figure 3). These features may represent the temporal 


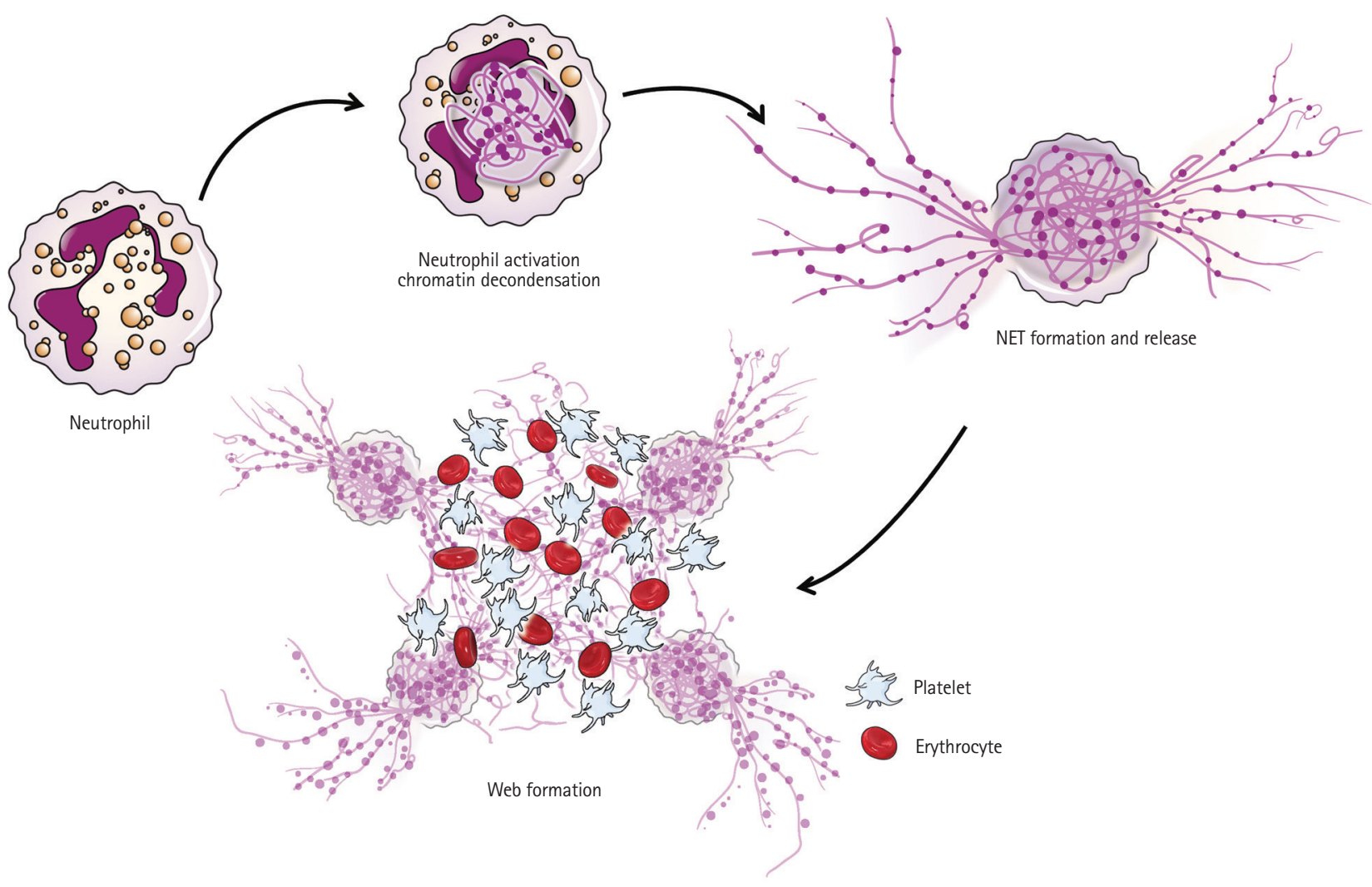

Figure 1. An illustration showing the process of neutrophil extracellular trap (NET) formation. NETs are formed within activated neutrophils, and then released from neutrophils. Released NETs form a web-like structure, which plays a role as a scaffold of thrombus. NETs also actively interact with platelets and erythrocytes to form thrombus.


Figure 2. Representative immunohistochemistry images of the human thrombus outlining (A) neutrophils (anti-myeloperoxidase) and (B) neutrophil extracellular traps (anti-histone H3). Areas expressing neutrophils are overlapped with those expressing neutrophil extracellular traps. Positive signals to primary antibodies were developed using 3,3'-diaminobenzidine, and are seen as areas of brown staining $(\times 400)$.

process of NET formation. NETs are at first formed within activated neutrophils, then show filopodia-like structure as they are released from neutrophils, and finally form a web-like structure (Figure 1). The activity of NETs increases as the number of neu- trophils increases, ${ }^{25}$ which suggests that web formation by NETs is facilitated as more neutrophils infiltrate into thrombus.

It is uncertain whether the proportion of NETs is different among different stroke etiologies. While one study has shown 

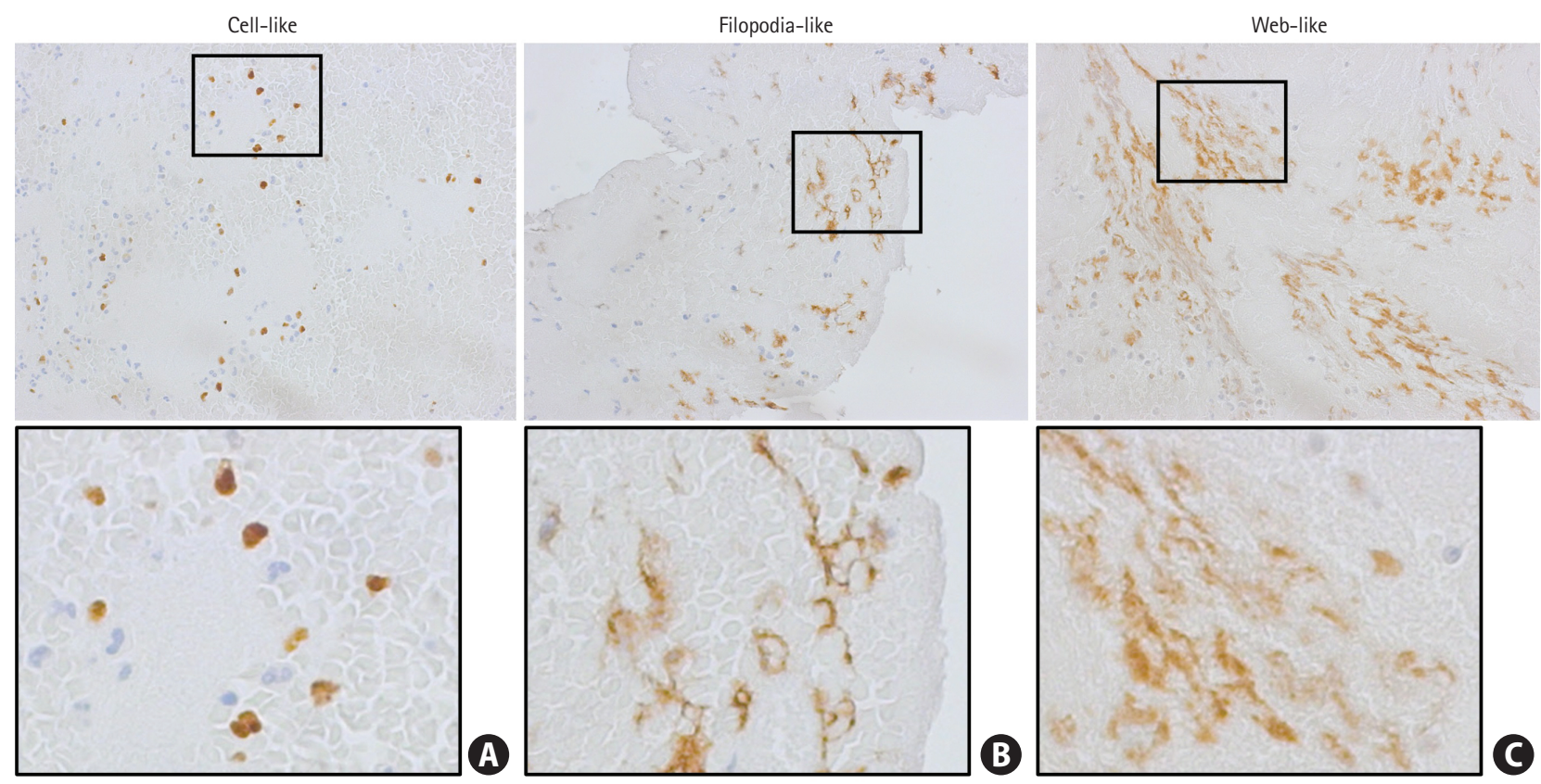

Figure 3. Variable features of neutrophil extracellular traps. Immunoreactivity to histone $\mathrm{H} 3$ (brown staining), representing neutrophil extracellular traps, is seen as (A) cell-like (within cells), (B) filopodia-like, or (C) web-like features. Lower panels are magnifications of the upper panel images ( $\times 400)$.

that NETs are more abundant in cardiogenic thrombi than in thrombi due to other causes, ${ }^{22}$ there was no association between NET content and stroke etiology in another study. ${ }^{33}$ Because older thrombi have more neutrophils and NETs than fresh thrombi, ${ }^{22}$ the thrombus age may be closely related to the amount of NET content in thrombi.

\section{Thrombus age and stroke etiology}

The thrombus age may differ according to the stroke etiology. Embolization may occur sooner or later after thrombus formation at the original site. Thrombus are often classified as fresh or lytic and organized according to its age and histologic features. A fresh thrombus ( $<1$ day) is composed of layered patterns of platelets, fibrin, erythrocytes, and intact granulocytes, a lytic thrombus ( 1 to 5 days) is characterized by areas of colliquation necrosis and karyorrhexis of granulocytes, and an organized thrombus ( $>5$ days) shows ingrowth of smooth muscle cells, with or without depositions of connective tissue and capillary vessel ingrowth. ${ }^{34}$

In a study that assessed thrombus as fresh, lytic, or organized, no significant differences were found in the thrombus age between the different subtypes of stroke.." Another study assessed the thrombus age based on leukocyte morphology and demonstrated that fresh or lytic forms of leukocytes were found in arterial thrombi, whereas most cardiac thrombi showed organized forms. ${ }^{13}$ The infiltration of leukocytes in- creases as the thrombus matures. When considering that leukocytes are more dominant in cardiac thrombus than in arterial thrombus, aged forms of thrombus may be more common in cardiac thrombi.

\section{Pathophysiologic speculations on the mechanism of thrombus formation via histologic assessment of thrombus}

The distribution pattern of thrombus components may be associated with hemodynamics, blood flow, shear, and turbulence at the site of thrombus formation. A few studies have assessed the distribution pattern of thrombus components and compared it between different stroke etiologies. In an earlier study based on H\&E staining, many patients $(17 / 25,75 \%)$ showed a pattern of layers or serpentine showing fibrin/platelet bands interspersed with accumulations of nucleated cells and erythrocyte-rich accumulations. However, there was no prevalence of a specific etiology. ${ }^{9}$ In another study using immunohistochemical staining for platelets, some differences were found between arterial and cardiac thrombi: the arterial thrombi commonly showed platelets located at the edge or periphery of the thrombus with erythrocytes masses in the center of the thrombi, whereas cardiac thrombi frequently showed scattered aggregations of platelets throughout the thrombi, appearing as variegated or clustered spots. ${ }^{13}$ 
The thrombus often shows a laminated or layered pattern microscopically, known as the lines of Zahn. The lines of Zahn are characterized by alternating layers of platelets (mixed with fibrin) and erythrocytes and form at sites of rapid blood flow including the heart and aorta. Although the lines of Zahn have been reported in saphenous venous thrombosis, ${ }^{35}$ they are less apparent in veins or smaller arteries.

The mechanisms of thrombosis in atrial fibrillation have been described in relation to the Virchow's triad and include an abnormal vessel wall (endothelial or endocardial damage), abnormal flow (flow stasis), and abnormal blood constituents (abnormalities in coagulation, platelets, and fibrinolysis). ${ }^{36}$ The contribution of various mechanisms to atrial fibrillation results in mixed-type thrombi formation with heterogeneous patterns and compositions according to the degree of contribution of each mechanism (vessel wall, flow, and blood constituents). However, it is likely that many of them show a layered pattern or clustered spots of platelet aggregates because thrombi are formed under the conditions of rapid and constant blood flow (Figure 4).

A large arterial thrombus is formed via a process different from cardiac thrombus formation. In the large artery, such as the internal carotid artery bifurcation, platelet aggregates are formed at the stenotic segment as a result of the interaction between platelets and various integrins on the endothelium and by the action of von Willebrand factor that is activated by shear stress. ${ }^{37,38}$ At the poststenotic segment, large erythrocyte masses may be formed by turbulent and slow blood flow. Tissue factor is also released upon the rupture of atherosclerotic plaques. The released tissue factor locally forms thrombin, which then activates platelets and induces fibrin formation. ${ }^{39}$ This process may result in a large erythrocyte mass and peripherally located platelets (Figure 3).

However, histologic findings of thrombi that are retrieved during endovascular thrombectomy may not reflect the whole mechanism of thrombosis in patients with arterial and cardiac thrombi. Thrombi that are subjected to histologic analyses are large because the patients have received endovascular treatment due to large artery occlusion; in addition, they were all retrievable. Smaller or nonretrievable thrombi might have different histology to that of larger and retrievable thrombi. Furthermore, diverse cardiac diseases cause thromboembolism, and thrombus histology may differ among different cardiac etiologies. Further studies with larger and more diverse patient groups may be necessary to better understand the histologic features and related mechanisms of thrombosis.

Thrombi obtained in patients with cancer-associated NBTE show very high platelet and low erythrocyte fractions. ${ }^{25,40}$ This suggests that platelets play a key role in the formation of vegetation. Tumor cells crosstalk with platelets. Tumor cells activate platelets and induce platelet aggregation, a process known as tumor cell-induced platelet aggregation. ${ }^{41}$ Tumor cells secrete platelet-activating mediators such as adenosine
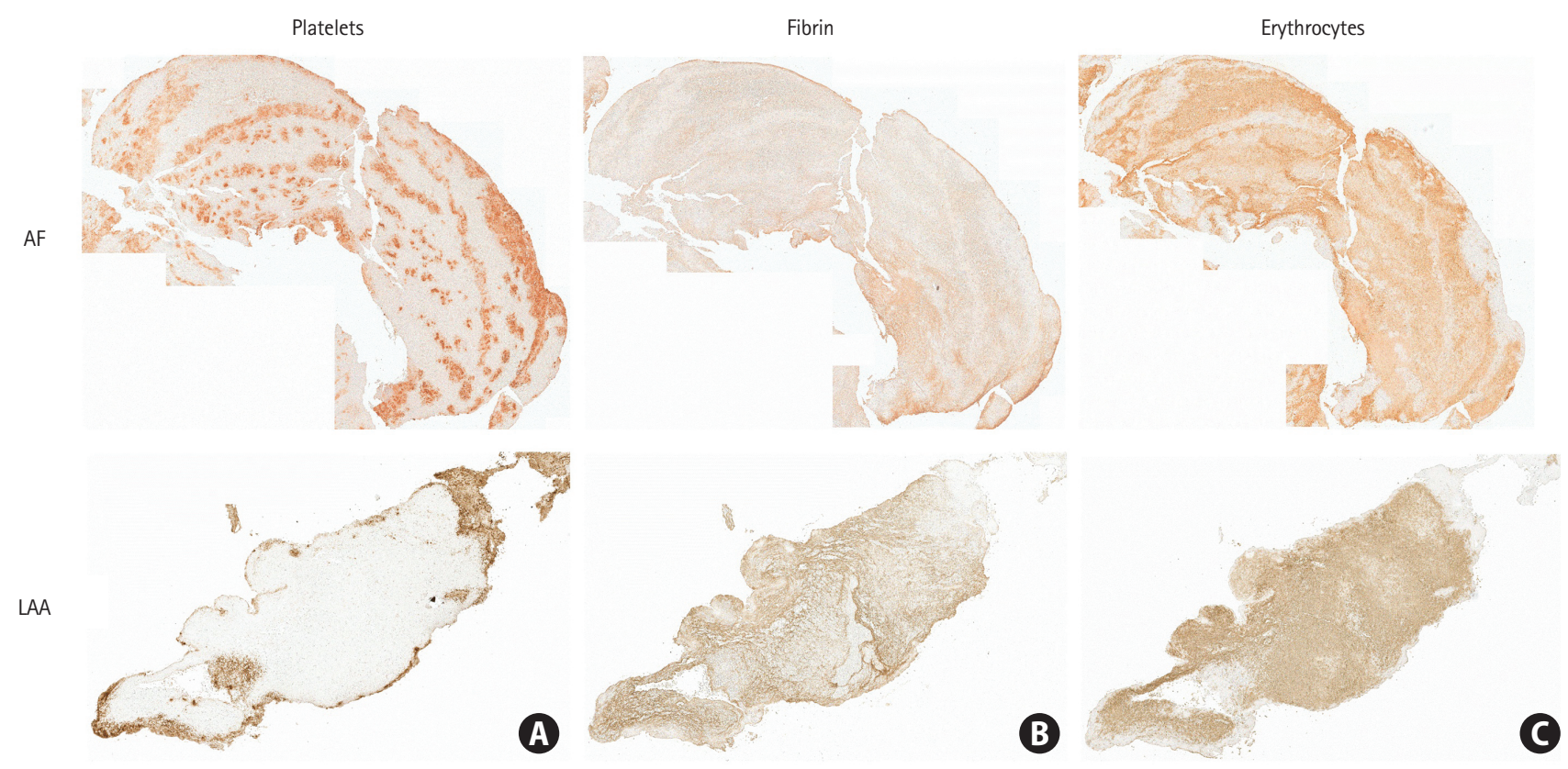

Figure 4. ( $A, B, C)$ Representative immunohistochemistry images of the human thrombus outlining platelets (anti-CD42b), erythrocytes (anti-glycophorin A), and fibrin/fibrinogen (anti-fibrinogen) in a patient with atrial fibrillation (AF) and large artery atherosclerosis (LAA). The staining in the patient with AF shows a layered pattern of clustered platelets, whereas that in the patient with LAA shows peripherally located platelets and a large erythrocyte mass ( $\times 400)$. 
diphosphate, thromboxane $\mathrm{A} 2$, and thrombin. ${ }^{42,43}$ Histological findings and evidence on cancer-platelet interaction indicate that platelets activated by tumor cells contribute to the development of platelet-rich vegetation.

\section{Thrombus composition and efficacy of endovascular thrombectomy}

\section{Erythrocytes and fibrin}

Several studies have investigated whether the efficacy of endovascular thrombectomy differs according to the thrombus composition. In earlier studies, no association was found between the proportion or dominancy of thrombus components and outcomes of mechanical thrombectomy using stent retrievers (procedure time, recanalization failure, and poor clinical outcome). ${ }^{12,44}$ In other studies, erythrocyte-rich thrombi were associated with a smaller number of recanalization maneuvers and shorter procedure times, ${ }^{15,16}$ as well as successful recanalization. ${ }^{45,46}$

In contrast, fibrin-rich thrombi with low erythrocyte fractions were associated with a longer interventional time and secondary embolism. ${ }^{15}$ In a recent study, thrombus fragments retrieved in each pass of a device were assessed separately. The erythrocyte composition was significantly higher in the thrombus retrieved in passes 1 and 2 than that retrieved in passes 3 or more. ${ }^{47}$ Furthermore, the fibrin composition was significantly lower in thrombus retrieved in passes 1 and 2 than that retrieved in passes 3 or more. These findings suggest that the erythrocyte-dominant portion of the thrombus was easily retrieved, whereas the fibrin-dominant portion was more resistant to retrieval. ${ }^{47}$ Removal of the thrombus depends on the thrombus-vessel interaction. ${ }^{48}$ Different friction properties between thrombus components may contribute to different response to thrombus retrieval between erythrocyte-rich and fibrin-rich thrombi. In experiments using an apparatus with gradual tilting, fibrin-dominant clots showed a greater coefficient of friction than erythrocyte-dominant clots. ${ }^{49}$

\section{Leukocytes and neutrophil extracellular traps}

Thrombi with a higher percentage of leukocytes or NETs were associated with an extended mechanical recanalization time, number of device passes, and less favorable recanalization. ${ }^{17,33,50}$ The amount of leukocytes and NETs may be associated with the thrombus age and degree of thrombus organization. As the thrombus is organized, the strength of adherence to the vessel wall may increase, making the removal or aspiration of thrombus more difficult. ${ }^{17}$

\section{Other thrombus components}

Calcified thrombi are rarely identified on non-contrast computed tomography (CT) before endovascular thrombectomy. In a small case series, stent retriever thrombectomy of calcified thromboemboli was associated with poor recanalization and an increased risk of periprocedural risk, including vessel perforation. ${ }^{51}$ The presence of endothelial cells was not associated with poor clinical outcomes. ${ }^{44}$

\section{Thrombus composition and periprocedural complications}

\section{Vessel wall injury during endovascular thrombectomy}

Thrombectomy using stent retrievers has a risk of vessel wall injury. This injury may occur during retraction of the stent retriever in relation to the radial force of the stent against the vessel wall, vascular anatomy, the presence of underlying stenosis, the occurrence of vasospasm, or underlying calcification of the vessel wall. Furthermore, vessel wall injury may result in arterial dissection, endothelial or intimal denudation and subsequent thrombosis, and vessel perforation. . $^{51,52}$

The occurrence of vessel wall injury was investigated by a histological analysis of retrieved thrombi. In a study of 48 thrombi retrieved by stent retrievers, no subendothelial vessel wall structures were found. ${ }^{44}$ However, in a total of 150 thrombi from 101 patients treated with penumbra or stent retrievers, vessel wall components (internal elastic lamina) were observed in 24 specimens (16\%) from 22 patients. Factors associated with vessel wall injury were a low proportion of erythrocyte components, high frequency of the devices reaching the $\mathrm{M} 2$ or P2 segment, and a high number of device passages. ${ }^{53}$ Angiographic and clinical outcomes did not differ between patients with thrombi containing vessel wall components and those with thrombi without these components. Further studies are necessary to determine the clinical significance of vessel wall injury during endovascular thrombectomy.

\section{Thrombus migration/fragmentation}

After the removal of thrombus from the primary occlusion site by mechanical thrombectomy, distal embolization or fragmentation of the thrombus may occur. Fragmentation or distal embolization may be related to the cohesiveness of the thrombus. Distal embolization is more frequent in cases with higher amounts of neutrophils within the thrombus, or in fibrin-rich thrombi with low erythrocyte fractions. ${ }^{15,50}$ The fraction of erythrocytes was not associated with distal embolization. ${ }^{50}$ 


\section{Thrombus composition in patients receiving intravenous thrombolysis}

Many patients receive bridging intravenous (IV) tissue plasminogen activator (tPA) before endovascular thrombectomy. Bridging tPA treatment before endovascular thrombectomy was associated with a significantly greater erythrocyte composition and lower fibrin composition. ${ }^{47,54,55}$ The thinning of fibrin layers was more common in patients treated with bridging IV tPA. ${ }^{56}$ In another study, the histologic characteristics of thrombus did not differ between patients who received bridging IV tPA therapy and those who did not. ${ }^{50}$ Moreover, content of the von Willebrand factor was not different between patients who received IV tPA and those who did not. ${ }^{57}$ Theoretically, tPA dissolves fibrin within the thrombus; therefore, a relatively lower fraction of fibrin is expected in patients who receive bridging IV tPA than in those who do not.

Previous studies have not assessed platelet fraction in patients receiving bridging IPA. However, activation of fibrinolysis by tPA treatment may paradoxically activate platelets. ${ }^{58}$ Plasminogen activator inhibitor-1 and a2-antiplasmin are also released ${ }^{59}$ which, in turn, may produce paradoxical thrombosis after IPA treatment in some patients with thrombus resistant to IPA. This paradoxical action of IPA is known as a key mechanism of reocclusion and rethrombosis after IPA treatment, which occurs in $22 \%$ to $34 \%$ of patients. ${ }^{60-63}$ In fact, in studies that measured the thrombus volume on CT before and immediately after IV IPA treatment, the thrombus was paradoxically enlarged in approximately $20 \%$ of patients. ${ }^{64,65}$ Patients who did not respond to IV tPA might have large or tPA-resistant thrombi. Thus, the platelet fraction may be higher in patients who received bridging IV tPA treatment. This hypothesis is partly supported by the very effective lysis of reocclusion following tPA treatment using potent platelet glycoprotein $\mathrm{Ilb} / \mathrm{Illa}$ receptor antagonists. ${ }^{61}$

When responsiveness to IV tPA was defined as an increase in the clot burden score, higher erythrocyte fractions were associated with better responsiveness to IV tPA. ${ }^{66}$

\section{Therapeutic perspectives}

\section{Thrombus age and targeting NETs}

Over time, cells and extracellular matrix molecules within the thrombus undergo microstructural changes. These changes may affect the response to recanalization treatment. Recent studies have indicated that leukocytes and NETs are more abundant in older thrombus, with older thrombi demonstrating more neutrophils and NETs than fresh thrombi. ${ }^{22}$ In a venous thrombosis model in mice, the number of neutrophils was the greatest at day 1, which, thereafter, gradually decreased. However, the number of macrophages peaked at 7 days. ${ }^{23}$

The thrombus age may be related to the response to recanalization treatment. In a study that measured thrombus volume on thin-section CT before and after IV TPA treatment, the probability of thrombus resolution decreased as the time interval from symptom onset to treatment increased. ${ }^{65}$ In patients with acute myocardial infarction, older thrombus aspirated during percutaneous coronary intervention was associated with impaired myocardial reperfusion. ${ }^{32}$ After initial thrombus formation, the thrombus is stabilized by further accumulation and crosslinking of fibrins by factor XIII. As a result, the thrombus becomes more compact and the pores become smaller. This causes lower penetration of tPA, which limits its fibrinolytic action. ${ }^{67,68}$ In addition, more neutrophils infiltrate into the thrombus over time, which subsequently form NETs.

Leukocytes and NETs may be associated with resistance to IV tPA. Among the two scaffolds of thrombus, the fibrin meshwork and NETs, TPA can lyse only fibrin. As such, it is expected that thrombi with abundant NETs may be resistant to tPA. Several studies have investigated whether thrombus can be lysed by treatment with deoxyribonuclease I (DNAse I), which can degrade NETs. In ex vivo studies using fresh thrombi obtained from stroke patients, the addition of DNAse I to tPA increased thrombus lysis compared to tPA alone. ${ }^{22,33}$ However, treatment with DNAse I alone had no thrombolytic effects. ${ }^{33}$ These findings suggest that adjunctive treatment with DNAse I can potentiate the effect of tPA.

\section{Cancer stroke}

Antithrombotic treatment in stroke patients with cancer may differ according to the underlying mechanism. Patients with NBTE show a very high platelet fraction in the thrombus. ${ }^{25}$ However, patients with determinable etiologies showed histologic findings of thrombus that were similar to those in patients with determined etiologies but without cancer. ${ }^{25}$ These findings suggest that active cancer may be a bystander in most patients with other obvious etiologies, such as atrial fibrillation and large artery atherosclerosis. In contrast, patients with a cryptogenic etiology had histologic findings similar to those with NBTE. ${ }^{25}$ NBTE is the most common etiology of stroke in autopsy studies of stroke patients with cancer and is suggested as the likely cause of stroke in many patients with cancer with a cryptogenic etiology. ${ }^{69}$ As such, it may be reasonable that a similar antithrombotic regimen is considered for stroke prevention in cancer patients with NBTE and a cryptogenic etiology. Patients without NBTE but with other obvious etiologies may 
be managed according to their known etiologies.

Current guidelines recommend anticoagulation with fulldose unfractionated heparin or subcutaneous low-molecular heparinoid over no anticoagulation in patients with NBTE. ${ }^{70}$ This recommendation is based on the general belief that NBTE is associated with coagulopathy and chronic disseminated coagulopathy. ${ }^{70,71}$ However, pathologic studies of cardiac vegetation and histologic findings of intracranial thrombi indicate that platelets play a crucial role in the development of vegetation. ${ }^{25,27}$ Patients with stroke and cancer tend to be adverse to receiving injection. ${ }^{72}$ In this regard, among stroke patients with active cancer, antiplatelet agents may be an alternative option for preventing recurrent stroke in patients with NBTE or those with a cryptogenic etiology. ${ }^{40}$

\section{Conclusions}

Recent advances in endovascular thrombectomy have opened a window for looking into fresh thrombus in patients with acute stroke. Consequently, this has elicited new perspectives on the mechanism of thrombus formation from a conceptual idea to a visible one. However, the window is still small, and thrombi obtained during mechanical thrombectomy are limited to those that are large and retrievable. More thrombus samples from patients with stroke of diverse etiologies are necessary to gain further insight into the pathophysiologic mechanism of different stroke etiologies. Furthermore, the standardization of the histologic examination of thrombus is also necessary. Translational research using fresh thrombi is also encouraged. Nevertheless, thrombus research is promising because it may provide valuable information for determining the treatment strategy of preventing recurrence in patients with stroke. It may also be helpful for the development of new thrombolytic agents targeting other than fibrin. Addition of DNAse- 1 that targets NETs may enhance thrombolytic effects of tPA. ${ }^{22,33}$ tPAresistant von Willebrand factor-rich thrombus may be effectively dissolved by ADAMTS13 (a disintegrin and metalloproteinase with a thrombospondin type 1 motif, member 13) that targets von Willebrand factor. ${ }^{57}$ Saxatilin targeting multiple integrins on platelets and leukocytes may also effectively dissolve thrombus by disaggregating platelet-fibrin binding and inhibiting platelet-leukocyte interaction. ${ }^{73}$

\section{Disclosure}

The authors have no financial conflicts of interest.

\section{Acknowledgments}

This research was supported by the Basic Science Research Program through the National Research Foundation of Korea (NRF) funded by the Ministry of Education (NRF-2018R1A2A3074996), and by a faculty research grant of Yonsei University College of Medicine (6-2018-0185).

The authors thank Medical Illustration \& Design, part of the Medical Research Support Services of Yonsei University College of Medicine, for all artistic support related to this work.

\section{References}

1. Goyal M, Menon BK, van Zwam WH, Dippel DW, Mitchell PJ, Demchuk AM, et al. Endovascular thrombectomy after largevessel ischaemic stroke: a meta-analysis of individual patient data from five randomised trials. Lancet 2016;387:1723-1731.

2. Andersson $T$, Wiesmann $M$, Nikoubashman 0 , Gopinathan $A$, Bhogal P, Yeo LLL. The aspirations of direct aspiration for thrombectomy in ischemic stroke: a critical analysis. J Stroke 2019;21:2-9.

3. Ko SB, Park HK, Kim BM, Heo JH, Rha JH, Kwon SU, et al. 2019 Update of the Korean clinical practice guidelines of stroke for endovascular recanalization therapy in patients with acute ischemic stroke. J Stroke 2019;21:231-240.

4. Powers WJ, Rabinstein AA, Ackerson T, Adeoye OM, Bambakidis NC, Becker K, et al. Guidelines for the early management of patients with acute ischemic stroke: 2019 update to the 2018 guidelines for the early management of acute ischemic stroke: a guideline for healthcare professionals from the American heart association/American stroke association. Stroke 2019;50:e344-e418.

5. Chung JW, Kim BJ, Jeong HG, Seo WK, Kim GM, Jung C, et al. Selection of candidates for endovascular treatment: characteristics according to three different selection methods. $J$ Stroke 2019;21:332-339.

6. Brinjikji W, Duffy S, Burrows A, Hacke W, Liebeskind D, Majoie CBLM, et al. Correlation of imaging and histopathology of thrombi in acute ischemic stroke with etiology and outcome: a systematic review. J Neurointerv Surg 2017;9:529-534.

7. Heo JH, Kim K, Yoo J, Kim YD, Nam HS, Kim EY. Computed tomography-based thrombus imaging for the prediction of recanalization after reperfusion therapy in stroke. J Stroke 2017;19:40-49.

8. De Meyer SF, Andersson T, Baxter B, Bendszus $M$, Brouwer $P_{1}$ Brinjikji $W$, et al. Analyses of thrombi in acute ischemic stroke: a consensus statement on current knowledge and future directions. Int J Stroke 2017;12:606-614. 
9. Marder VJ, Chute DJ, Starkman S, Abolian AM, Kidwell C, Liebeskind $D$, et al. Analysis of thrombi retrieved from cerebral arteries of patients with acute ischemic stroke. Stroke 2006; 37:2086-2093.

10. Liebeskind DS, Sanossian N, Yong WH, Starkman S, Tsang $M P$, Moya $A L$, et al. $C T$ and $M R I$ early vessel signs reflect clot composition in acute stroke. Stroke 2011;42:1237-1243.

11. Niesten JM, van der Schaaf IC, van Dam L, Vink A, Vos JA, Schonewille WJ, et al. Histopathologic composition of cerebral thrombi of acute stroke patients is correlated with stroke subtype and thrombus attenuation. PLoS One 2014;9: e88882.

12. Kim SK, Yoon W, Kim TS, Kim HS, Heo TW, Park MS. Histologic analysis of retrieved clots in acute ischemic stroke: correlation with stroke etiology and gradient-echo MRI. AJNR Am J Neuroradiol 2015;36:1756-1762.

13. Ahn SH, Hong R, Choo IS, Heo JH, Nam HS, Kang HG, et al. Histologic features of acute thrombi retrieved from stroke patients during mechanical reperfusion therapy. Int J Stroke 2016;11:1036-1044.

14. Boeckh-Behrens T, Kleine JF, Zimmer C, Neff F, Scheipl F, Pelisek J, et al. Thrombus histology suggests cardioembolic cause in cryptogenic stroke. Stroke 2016;47:1864-1871.

15. Sporns PB, Hanning U, Schwindt W, Velasco A, Buerke B,

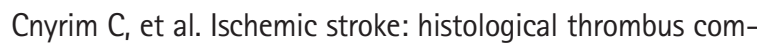
position and pre-interventional ct attenuation are associated with intervention time and rate of secondary embolism. Cerebrovasc Dis 2017;44:344-350.

16. Maekawa $K$, Shibata $M$, Nakajima $H$, Mizutani $A$, Kitano $Y$, Seguchi $M$, et al. Erythrocyte-rich thrombus is associated with reduced number of maneuvers and procedure time in patients with acute ischemic stroke undergoing mechanical thrombectomy. Cerebrovasc Dis Extra 2018;8:39-49.

17. Boeckh-Behrens T, Schubert M, Förschler A, Prothmann S,

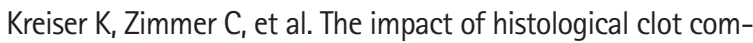
position in embolic stroke. Clin Neuroradiol 2016;26:189-197.

18. Sato $Y$, Ishibashi-Ueda $H$, Iwakiri $T$, Ikeda $Y$, Matsuyama $T$, Hatakeyama K, et al. Thrombus components in cardioembolic and atherothrombotic strokes. Thromb Res 2012;130:278280.

19. Sporns PB, Hanning U, Schwindt W, Velasco A, Minnerup J, Zoubi $T_{1}$ et al. Ischemic stroke: what does the histological composition tell us about the origin of the thrombus? Stroke 2017;48:2206-2210.

20. Schuhmann MK, Gunreben I, Kleinschnitz C, Kraft P. Immunohistochemical analysis of cerebral thrombi retrieved by mechanical thrombectomy from patients with acute ischemic stroke. Int J Mol Sci 2016;17:298.
21. Dargazanli C, Rigau V, Eker O, Riquelme Bareiro C, Machi $P$, Gascou G, et al. High CD3+ cells in intracranial thrombi represent a biomarker of atherothrombotic stroke. PLoS One 2016;11:e0154945.

22. Laridan E, Denorme F, Desender L, François O, Andersson T, Deckmyn $\mathrm{H}_{\text {, et }}$ al. Neutrophil extracellular traps in ischemic stroke thrombi. Ann Neurol 2017;82:223-232.

23. Nosaka M, Ishida Y, Kimura A, Kondo T. Time-dependent appearance of intrathrombus neutrophils and macrophages in a stasis-induced deep vein thrombosis model and its application to thrombus age determination. Int J Legal Med 2009; 123:235-240.

24. Navi BB, Reiner AS, Kamel H, ladecola C, Okin PM, Elkind MSV, et al. Risk of arterial thromboembolism in patients with cancer. J Am Coll Cardiol 2017;70:926-938.

25. Park H, Kim J, Ha J, Hwang IG, Song TJ, Yoo J, et al. Histological features of intracranial thrombi in stroke patients with cancer. Ann Neurol 2019;86:143-149.

26. Biller J, Challa VR, Toole JF, Howard VJ. Nonbacterial thrombotic endocarditis. A neurologic perspective of clinicopathologic correlations of 99 patients. Arch Neurol 1982;39:9598.

27. Rogers $L R$, Cho ES, Kempin S, Posner JB. Cerebral infarction from non-bacterial thrombotic endocarditis. Clinical and pathological study including the effects of anticoagulation. Am J Med 1987;83:746-756.

28. Navi BB, Singer $S$, Merkler AE, Cheng NT, Stone JB, Kamel $H$, et al. Recurrent thromboembolic events after ischemic stroke in patients with cancer. Neurology 2014;83:26-33.

29. Graus F, Rogers LR, Posner JB. Cerebrovascular complications in patients with cancer. Medicine (Baltimore) 1985;64:16-35.

30. Martinod K, Wagner DD. Thrombosis: tangled up in NETs. Blood 2014;123:2768-2776.

31. Fuchs TA, Brill A, Duerschmied D, Schatzberg D, Monestier M, Myers DD Jr, et al. Extracellular DNA traps promote thrombosis. Proc Natl Acad Sci U S A 2010;107:15880-15885.

32. Laridan E, Martinod K, De Meyer SF. Neutrophil extracellular traps in arterial and venous thrombosis. Semin Thromb Hemost 2019;45:86-93.

33. Ducroux C, Di Meglio L, Loyau S, Delbosc S, Boisseau W, Des-

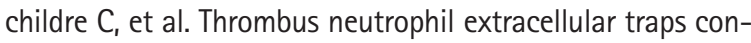
tent impair tpa-induced thrombolysis in acute ischemic stroke. Stroke 2018;49:754-757.

34. Rittersma SZ, van der Wal AC, Koch KT, Piek JJ, Henriques JP, Mulder KJ, et al. Plaque instability frequently occurs days or weeks before occlusive coronary thrombosis: a pathological thrombectomy study in primary percutaneous coronary intervention. Circulation 2005;111:1160-1165. 
35. Rashidi A, Gilles S, Linden MA. Lines of Zahn in the splenic vein. Thromb Haemost 2018;118:957-958.

36. Khan AA, Lip GYH. The prothrombotic state in atrial fibrillation: pathophysiological and management implications. Cardiovasc Res 2019;115:31-45.

37. Jamasbi J, Ayabe K, Goto S, Nieswandt B, Peter K, Siess W. Platelet receptors as therapeutic targets: past, present and future. Thromb Haemost 2017;117:1249-1257.

38. Nieswandt B, Pleines I, Bender M. Platelet adhesion and activation mechanisms in arterial thrombosis and ischaemic stroke. J Thromb Haemost 2011;9 Suppl 1:92-104.

39. Badimon L, Vilahur G. Thrombosis formation on atherosclerotic lesions and plaque rupture. J Intern Med 2014;276:618632.

40. Kim K, Kim J, Ahn SH, Ha WS, Koo YJ, Kim DJ, et al. Histopathological findings of intracranial thrombi in nonbacterial thrombotic endocarditis. J Stroke 2017;19:367-369.

41. Jurasz $P$, Alonso-Escolano D, Radomski MW. Platelet: cancer interactions: mechanisms and pharmacology of tumour cellinduced platelet aggregation. Br J Pharmacol 2004;143:819826.

42. Egan K, Cooke N, Kenny D. Living in shear: platelets protect cancer cells from shear induced damage. Clin Exp Metastasis 2014;31:697-704.

43. Mitrugno A, Williams D, Kerrigan SW, Moran N. A novel and essential role for FcyRlla in cancer cell-induced platelet activation. Blood 2014;123:249-260.

44. Singh $P_{1}$ Doostkam $S$, Reinhard $M$, Ivanovas $V_{1}$ Taschner $C A$. Immunohistochemical analysis of thrombi retrieved during treatment of acute ischemic stroke: does stent-retriever cause intimal damage? Stroke 2013;44:1720-1722.

45. Shin JW, Jeong HS, Kwon HJ, Song KS, Kim J. High red blood cell composition in clots is associated with successful recanalization during intra-arterial thrombectomy. PLoS One 2018;13:e0197492.

46. Hashimoto $T$, Hayakawa M, Funatsu $N$, Yamagami H, Satow T, Takahashi JC, et al. Histopathologic analysis of retrieved thrombi associated with successful reperfusion after acute stroke thrombectomy. Stroke 2016;47:3035-3037.

47. Duffy $S$, McCarthy $R$, Farrell M, Thomas S, Brennan P, Power $\mathrm{S}$, et al. Per-pass analysis of thrombus composition in patients with acute ischemic stroke undergoing mechanical thrombectomy. Stroke 2019;50:1156-1163.

48. Yoo AJ, Andersson T. Thrombectomy in acute ischemic stroke: challenges to procedural success. J Stroke 2017;19:121-130.

49. Gunning GM, McArdle K, Mirza M, Duffy S, Gilvarry M, Brouwer PA. Clot friction variation with fibrin content; implications for resistance to thrombectomy. J Neurointerv Surg
2018;10:34-38.

50. Kaesmacher J, Boeckh-Behrens T, Simon S, Maegerlein C, Kleine JF, Zimmer $C_{\text {, et }}$ al. Risk of thrombus fragmentation during endovascular stroke treatment. AJNR Am J Neuroradiol 2017;38:991-998.

51. Dobrocky T, Piechowiak E, Cianfoni A, Zibold F, Roccatagliata $L$, Mosimann $P$, et al. Thrombectomy of calcified emboli in stroke. Does histology of thrombi influence the effectiveness of thrombectomy? J Neurointerv Surg 2018;10:345-350.

52. Koge J, Kato S, Hashimoto T, Nakamura Y, Kawajiri M, Yamada T. Vessel wall injury after stent retriever thrombectomy for internal carotid artery occlusion with duplicated middle cerebral artery. World Neurosurg 2019;123:54-58.

53. Funatsu $N$, Hayakawa $M$, Hashimoto $T$, Yamagami $H$, Satow T, Takahashi JC, et al. Vascular wall components in thrombi obtained by acute stroke thrombectomy: clinical significance and related factors. J Neurointerv Surg 2019;11:232-236.

54. Horie N, Shobayashi K, Morofuji Y, Sadakata E, Iki Y, Matsunaga $Y$, et al. Impact of mechanical thrombectomy device on thrombus histology in acute embolic stroke. World Neurosurg 2019;132:e418-e422.

55. Qureshi Al, Qureshi MH, Lobanova I, Bashir A, Khan AA, Bologna $S M$, et al. Histopathological characteristics of IV recombinant tissue plasminogen: resistant thrombi in patients with acute ischemic stroke. J Vasc Interv Neurol 2016;8:3845.

56. Krajičková $D$, Krajina $A$, Šteiner I, Vyšata 0 , Herzig R, Lojík $M$, et al. Fibrin clot architecture in acute ischemic stroke treated with mechanical thrombectomy with stent-retrievers: cohort study. Circ J 2018;82:866-873.

57. Denorme F, Langhauser F, Desender L, Vandenbulcke A, Rottensteiner $\mathrm{H}$, Plaimauer $\mathrm{B}$, et al. ADAMTS13-mediated thrombolysis of t-PA-resistant occlusions in ischemic stroke in mice. Blood 2016;127:2337-2345.

58. Coller BS. Platelets and thrombolytic therapy. N Engl J Med 1990;322:33-42.

59. Szabo S, Etzel D, Ehlers R, Walter T, Kazmaier S, Helber U, et al. Increased fibrin specificity and reduced paradoxical thrombin activation of the combined thrombolytic regimen with reteplase and abciximab versus standard reteplase thrombolysis. Drugs Exp Clin Res 2004;30:47-54.

60. Alexandrov AV, Grotta JC. Arterial reocclusion in stroke patients treated with intravenous tissue plasminogen activator. Neurology 2002;59:862-867.

61. Heo JH, Lee KY, Kim SH, Kim DI. Immediate reocclusion following a successful thrombolysis in acute stroke: a pilot study. Neurology 2003;60:1684-1687.

62. Qureshi Al, Hussein HM, Abdelmoula M, Georgiadis AL, Jan- 
jua N. Subacute recanalization and reocclusion in patients with acute ischemic stroke following endovascular treatment. Neurocrit Care 2009;10:195-203.

63. Saqqur M, Molina CA, Salam A, Siddiqui M, Ribo M, Uchino $K_{1}$ et al. Clinical deterioration after intravenous recombinant tissue plasminogen activator treatment: a multicenter transcranial Doppler study. Stroke 2007;38:69-74.

64. Nam HS, Kim EY, Kim SH, Kim YD, Kim J, Lee HS, et al. Prediction of thrombus resolution after intravenous thrombolysis assessed by CT-based thrombus imaging. Thromb Haemost 2012;107:786-794.

65. Kim YD, Nam HS, Kim SH, Kim EY, Song D, Kwon I, et al. Time-dependent thrombus resolution after tissue-type plasminogen activator in patients with stroke and mice. Stroke 2015;46:1877-1882.

66. Choi MH, Park GH, Lee JS, Lee SE, Lee SJ, Kim JH, et al. Erythrocyte fraction within retrieved thrombi contributes to thrombolytic response in acute ischemic stroke. Stroke 2018; 49:652-659.

67. Collet JP, Allali Y, Lesty C, Tanguy ML, Silvain J, Ankri A, et al. Altered fibrin architecture is associated with hypofibrinolysis and premature coronary atherothrombosis. Arterioscler Thromb Vasc Biol 2006;26:2567-2573.
68. Varjú I, Sótonyi P, Machovich R, Szabó L, Tenekedjiev K, Silva $M M$, et al. Hindered dissolution of fibrin formed under mechanical stress. J Thromb Haemost 2011;9:979-986.

69. Navi BB, ladecola C. Ischemic stroke in cancer patients: a review of an underappreciated pathology. Ann Neurol 2018; 83:873-883.

70. Whitlock RP, Sun JC, Fremes SE, Rubens FD, Teoh KH. Antithrombotic and thrombolytic therapy for valvular disease: antithrombotic therapy and prevention of thrombosis, 9th ed: american college of chest physicians evidence-based clinical practice guidelines. Chest 2012;141:e576S-e600S.

71. Sack GH Jr, Levin J, Bell WR. Trousseau's syndrome and other manifestations of chronic disseminated coagulopathy in patients with neoplasms: clinical, pathophysiologic, and therapeutic features. Medicine (Baltimore) 1977;56:1-37.

72. Navi BB, Marshall RS, Bobrow D, Singer S, Stone JB, DeSancho MT, et al. Enoxaparin vs aspirin in patients with cancer and ischemic stroke: the TEACH pilot randomized clinical trial. JAMA Neurol 2018;75:379-381.

73. Kwon I, Hong SY, Kim YD, Nam HS, Kang S, Yang SH, et al. Thrombolytic effects of the snake venom disintegrin saxatilin determined by novel assessment methods: a FeCl3-induced thrombosis model in mice. PLoS One 2013;8:e81165. 